\title{
Evaluation of Various Factors Leading to Osteolytic and Antiosteolytic Effects in Patients With Rheumatoid Arthritis
}

\author{
Kazım Serkan SUNAL, ${ }^{1}$ Ayşen CANIKLİĞLU, ${ }^{2}$ Hüseyin DEMİR, ${ }^{3}$ Emre ERSOY, ${ }^{3}$ Derya KOÇER, ${ }^{4}$ \\ Kıymet DOLBUN SEÇKİN, ${ }^{1}$ Aysun ŞAHİN SUNAL, ${ }^{1}$ Gülden BAŞKOL ${ }^{2}$ \\ ${ }^{1}$ Institute of Health Sciences, Erciyes University, Kayseri, Turkey \\ ${ }^{2}$ Department of Biochemistry, Medical Faculty of Erciyes University, Kayseri, Turkey \\ ${ }^{3}$ Department of Physical Medicine and Rehabilitation, Medical Faculty of Erciyes University, Kayseri, Turkey \\ ${ }^{4}$ Department of Biochemistry, Kayseri Training and Research Hospital, Kayseri, Turkey
}

\begin{abstract}
Objectives: This study aims to evaluate the biomarkers of bone formation and resorption to determine the mechanism of bone deformities in patients with rheumatoid arthritis (RA).

Patients and methods: Thirty patients ( 9 males, 21 females; mean age, 51.5 years; range 23 to 73 years) with RA and 19 healthy individuals ( 7 males, 12 females; mean age 51 years; range 24 to 61 years) were included in this study. Patients with RA were subgrouped according to disease activity (active, $n=21$, mean age 53.0; range 37 to 73 years; inactive, $n=9$, mean age 46.0; range 23 to 62 years). Levels of receptor activator of nuclear factor kappa B ligand (RANKL), osteoprotegerin (OPG), tartrate-resistant acid phosphatase-5b, tumor necrosis factor-alpha (TNF-a), cathepsin-K, and activity of matrix metalloproteinase-3 (MMP-3) were measured in patient and control groups with enzyme-linked immunosorbent assay method.

Results: Levels of RANKL, OPG, cathepsin-K, TNF- $a$ and MMP-3 activities of the patients were significantly higher when compared with the controls $(p<0.05)$. A comparison of the active and inactive patients with RA revealed that OPG levels and MMP-3 activities were significantly higher in active group than inactives $(p<0.05)$, while there was no significant difference in TNF- $a$, RANKL levels, and tartrate-resistant acid phosphatase-5b and cathepsin-K activities between two groups ( $p>0.05$ ).

Conclusion: Increased RANKL, OPG, TNF- $a$, cathepsin-K levels and MMP-3 activities in RA patients demonstrated that these parameters are related to bone deformities which occur in the process of RA. Widespread use of these parameters may be beneficial for the early diagnosis and effective treatment of RA and similar diseases resulting in bone deformities in the future.

Keywords: Cathepsin-K; matrix metalloproteinase-3; receptor activator of nuclear factor kappa B ligand; rheumatoid arthritis; tumor necrosis factor alpha.
\end{abstract}

Rheumatoid arthritis (RA) is a common chronic autoimmune disorder characterized by synovial inflammation. Bone loss in the inflamed joints occurs in the early stage of the disease, followed by the destruction of articular cartilage and bones. ${ }^{1,2}$ The pathogenesis of this disabling disease is not well understood, various genetic, epigenetic and environmental factors are thought to play a role in the establishment of RA. ${ }^{3}$

An abnormal proliferation of $\mathrm{T}$ cells which causes differentiation and maturation of osteoclasts is an important characteristic of RA.
T cells secrete soluble cytokines such as receptor activator of nuclear factor kappa B ligand (RANKL), tumor necrosis factor alpha (TNF- $\alpha$ ) and thereby directly induce the formation and differentiation of osteoclasts. ${ }^{4}$ RANKL is critical for the bone resorption process. It interacts with its receptor activator of nuclear factor kappa B (RANK) and so stimulates osteoclast migration, fusion, activation and survival. ${ }^{5,6}$ Osteoprotegerin (OPG) is a soluble glycoprotein which blocks the RANKL/RANK interaction and inhibits the activation of osteoclast. ${ }^{7}$ It is a protein with

Received: April 24, 2014 Accepted: June 30, 2014 Published online: January 08, 2015

Correspondence: Derya Koçer, M.D. Kayseri Eğitim ve Araştırma Hastanesi Biyokimya Bölümü, 38010 Kocasinan, Kayseri, Turkey.

Tel: +90 352 - 3368884 e-mail: ayder78@yahoo.com

○2015 Turkish League Against Rheumatism. All rights reserved. 
homology to members of the TNF receptor family and secreted by many cell types in addition to osteoblasts. $^{8}$

Cathepsin $\mathrm{K}$ is a tissue specific protease. Since cathepsin $\mathrm{K}$ plays an essential role in osteoclast function and in the degradation of protein components of the bone matrix, it has an important role in bone remodeling and resorption in diseases such as osteoporosis and inflammatory arthritis. ${ }^{9,10}$

Matrix metalloproteinases (MMPs) are critically involved in extracellular matrix breakdown and production, act as key mediators of the resorption of cartilage, bone and synovial fluid. ${ }^{11}$ MMP-3 can degrade many components of the extracellular matrix, and plays a key role in cartilage and joint destruction. ${ }^{12}$

Tartrate-resistant acid phosphatase (TRAP) belongs to a family of acid phosphatase isoenzymes found in bone, and is an iron-containing enzyme expressed in bone resorbing osteoclasts. ${ }^{13,14}$ Human TRAP exists as two distinct isoforms, $5 a$ and $5 b$. TRAP- $5 b$ is derived from osteoclasts, and has been used as a potential marker to assess the bone resorption rate. ${ }^{14}$

Tumor necrosis factor is one of the more potent osteoclastogenic cytokines produced in the setting of inflammation that plays an important role in the pathogenesis of autoimmune inflammatory diseases. TNF- $\alpha$ is an activating factor for the osteoclast and key mediator of inflammation process in patients with inflammatory arthritis. ${ }^{15,16}$

Various studies have aimed to clarify the mechanisms of bone deformities in RA. To the best of our knowledge, the levels of OPG, RANKL, TRAP-5b, TNF- $\alpha$, cathepsin $\mathrm{K}$ and MMP-3 activity in RA have not been studied together. Therefore, in this study, we aimed to evaluate the biomarkers of bone formation and resorption to determine the mechanism of bone deformities in patients with RA.

\section{PATIENTS AND METHODS}

Thirty patients (9 males, 21 females; mean age, 51.5 years; range 23 to 73 years) with RA from the Physical Medicine and Rehabilitation Department of Erciyes University Medical Faculty were included after they had given informed consent. The local ethics committee approved the study protocol (No: 2011/439), and the study was performed in accordance with the Declaration of Helsinki. Nineteen healthy subjects $(7$ males, 12 females; mean age 51 years; range 24 to 61 years) were also included as the control group.

Patients were selected according to the American College of Rheumatology criteria. ${ }^{17}$ Before the study, a complete blood count, routine biochemical analyses, C-reactive protein (CRP) level and erythrocyte sedimentation rate (ESR) testing were performed in all patients. None of the patients had any other systemic disease. Other exclusion criteria were systemic steroid usage, menopause, cigarette smoking or excessive alcohol usage.

All patients were subgrouped as active $(n=21$, mean age 53.0 years; range 37 to 73 years) and inactive ( $\mathrm{n}=9$, mean age 46.0 years; range 23 to 62 years) according to their CRP and ESR levels. A CRP level $>8 \mathrm{mg} / \mathrm{L}$ and ESR $>20 \mathrm{~mm} / \mathrm{h}$ were accepted as indicating the active stage of the disease. The Rheumatoid Arthritis Disease Activity Index (RADAI) was used for patient and physician assessment of disease activity. ${ }^{18}$

All blood samples were collected in the morning after an overnight fast and serum samples were stored at $-70{ }^{\circ} \mathrm{C}$ until assay for analysis. Serum levels of OPG (Adipo Bioscience, Santa Clara, CA, USA), RANKL (Biovendor, Candler, NC, USA), TNF- $\alpha$ (Avi Bion, Helsinki, Finland), cathepsin-K (Cusabio, Biotech CO., Ltd., Wuhan, Hubei, China), TRAP-5b (Quidel, Los Angeles, CA, USA) and MMP-3 activity (eBioscience, Vienna, Austria) were measured using commercial enzyme-linked immunosorbent assay, according to the manufacturer's instructions and carried out in duplicate.

Routine biochemical parameters were measured by an autoanalyzer (Architect c16000, Abbott Laboratories, Abbott Park, IL, USA) with original kits.

\section{Statistical analysis}

Statistical evaluation was carried out with the SPSS version 15.0 software program (SPSS Inc., Chicago, Illinois, USA). For comparison of all the variables between patient and control groups, Student's t-test was used. Mann Whitney U test was used for non-normally distributed parameters. 
Spearman correlation analysis was used to explore correlations between the variables. Data were presented as mean \pm standard deviation. $P$ value less than 0.05 was considered as statistically significant.

\section{RESULTS}

There was no statistical difference in age and sex distribution between controls and patients, and also among RA subgroups ( $p>0.05$ ). Serum OPG, RANKL, TNF- $\alpha$ levels and MMP-3, cathepsin K activities were significantly higher in patients with RA than in the controls $(p<0.001, p<0.035$, $\mathrm{p}<0.002, \mathrm{p}<0.001, \mathrm{p}<0.001$, respectively). No difference in TRAP-5b activities was observed between the patient and the control groups ( $p>0.05)$ (Table 1).

When subgroups were compared, OPG level and MMP-3 activities were significantly higher in active group than inactive group (Table 2). No differences in serum levels of RANKL, TRAP-5b, TNF- $\alpha$ and cathepsin $\mathrm{K}$ activities were observed between subgroups.

According to the results of correlation analyses in patient group, there was no correlation between inflammatory parameters of CRP and
ESR, and OPG, RANKL, TNF- $\alpha$, MMP-3, and cathepsin $\mathrm{K}$.

\section{DISCUSSION}

Rheumatoid arthritis is a common systemic autoimmune disease characterized by the destruction of articular cartilage and bone. It has been shown that osteoclasts were responsible for bone destruction in RA patients, ${ }^{19}$ and for osteoclast differentiation, an increase in RANKL secretion is necessary. ${ }^{4}$ OPG acts as an effective inhibitor of osteoclast activation and bone resorption by binding with high affinity to RANKL. ${ }^{6}$ Our data demonstrated that the serum levels of RANKL and OPG were significantly higher in patients with RA than the controls, indicating that the RANKL-OPG system plays a critical role in the pathogenesis of RA. Elevated serum levels of RANKL and OPG have been reported in patients with RA previously. ${ }^{20,21}$ We also found significantly elevated OPG level in active group than inactives. Based on the results of our study, it is possible that a higher amount of sRANKL requires more OPG to block its biologic activity. To compensate the RANKL-mediated bone degradation, OPG overproduction occurs due to its protective role.

Table 1. Clinical and laboratory characteristics of rheumatoid arthritis patients and controls

\begin{tabular}{|c|c|c|c|c|c|c|c|}
\hline & \multicolumn{3}{|c|}{ Patients with RA $(n=30)$} & \multicolumn{3}{|c|}{ Controls $(\mathrm{n}=19)$} & \multirow[b]{2}{*}{$p$} \\
\hline & Median & Range & Mean \pm SD & Median & Range & Mean \pm SD & \\
\hline Age (year) & & & $51.67 \pm 10.84$ & & & $49.58 \pm 10.19$ & 0.505 \\
\hline Weight (kg) & & & $72.00 \pm 14.95$ & & & $67.72 \pm 11.13$ & 0.299 \\
\hline Height $(\mathrm{cm})$ & & & $164.00 \pm 0.10$ & & & $162.58 \pm 0.07$ & 0.584 \\
\hline BMI $\left(\mathrm{kg} / \mathrm{m}^{2}\right)$ & 25.90 & 22.94-27.99 & & 24.46 & $22.86-29.40$ & & 0.805 \\
\hline $\mathrm{ESR}(\mathrm{mm} / \mathrm{h})$ & 31.50 & $19.00-63.00$ & & 3.00 & $2.00-8.00$ & & 0.001 \\
\hline $\mathrm{CRP}(\mathrm{mg} / \mathrm{L})$ & 10.78 & $3.34-26.00$ & & 3.34 & $3.34-3.34$ & & 0.002 \\
\hline ALP (IU/L) & 95.50 & $80.25-119.75$ & & 57.00 & $48.00-97.00$ & & 0.004 \\
\hline BUN (mg/dL) & 15.00 & $10.75-17.00$ & & 12.00 & $9.00-15.00$ & & 0.066 \\
\hline Creatinine (mg/dL) & 0.66 & $0.60-0.84$ & & 0.69 & $0.66-0.80$ & & 0.472 \\
\hline $\mathrm{OPG}(\mathrm{pg} / \mathrm{mL})$ & 1716.88 & $1372.60-2277.81$ & & 765.83 & $529.38-868.44$ & & 0.001 \\
\hline RANKL (pmol/L) & 2.78 & $1.42-6.30$ & & 1.83 & $0.77-2.63$ & & 0.035 \\
\hline MMP-3 (ng/mL) & 45.64 & $19.36-52.15$ & & 8.95 & $3.71-14.56$ & & 0.001 \\
\hline TRAP-5b (U/L) & & & $2.23 \pm 0.97$ & & & $2.80 \pm 1.01$ & 0.065 \\
\hline TNF- $\alpha(\mathrm{pg} / \mathrm{mL})$ & 154.67 & $106.92-220.75$ & & 103.33 & $70.00-140.33$ & & 0.002 \\
\hline Cathepsin K & 228.77 & $136.81-331.05$ & & 80.95 & $70.63-118.65$ & & 0.001 \\
\hline
\end{tabular}


Table 2. Comparison of rheumatoid arthritis patients with respect to disease activity

\begin{tabular}{|c|c|c|c|c|c|c|c|}
\hline & \multicolumn{3}{|c|}{ Active patients $(n=21)$} & \multicolumn{3}{|c|}{ Inactive patients $(n=9)$} & \multirow[b]{2}{*}{$p$} \\
\hline & Median & Range & Mean \pm SD & Median & Range & Mean \pm SD & \\
\hline Age (year) & & & $54.29 \pm 9.98$ & & & $45.56 \pm 10.80$ & 0.041 \\
\hline Weight (kg) & & & $73.05 \pm 15.69$ & & & $69.56 \pm 13.62$ & 0.567 \\
\hline Height (cm) & & & $163.38 \pm 9.79$ & & & $165.44 \pm 10.29$ & 0.606 \\
\hline $\operatorname{BMI}\left(\mathrm{kg} / \mathrm{m}^{2}\right)$ & 25.39 & $22.85-31.05$ & & 26.81 & $23.26-27.14$ & & 0.790 \\
\hline ESR (mm/h) & 53.00 & $29.50-81.00$ & & 13.00 & $11.00-19.00$ & & 0.001 \\
\hline $\mathrm{CRP}(\mathrm{mg} / \mathrm{L})$ & 20.60 & 6.1933 .15 & & 3.34 & $3.30-4.46$ & & 0.001 \\
\hline ALP (U/L) & 104.00 & $87.00-122.00$ & & 82.00 & $65.00-106.00$ & & 0.050 \\
\hline BUN (mg/dL) & 16.00 & $12.50-20.50$ & & 11.00 & $8.00-15.50$ & & 0.050 \\
\hline Creatinine (mg/dL) & 0.68 & $0.61-0.94$ & & 0.66 & $0.55-0.78$ & & 0.326 \\
\hline OPG (pg/mL) & 1833 & $1555.42-2462.71$ & & 1358.54 & $872.08-1742.92$ & & 0.032 \\
\hline RANKL (pmol/L) & 2.76 & $1.41-4.75$ & & 2.84 & $1.02-7.25$ & & 0.962 \\
\hline MMP-3 (ng/mL) & & & $43.37 \pm 17.92$ & & & $27.07 \pm 18.37$ & 0.031 \\
\hline TRAP-5b (U/L) & & & $2.10 \pm 1.01$ & & & $2.56 \pm 0.82$ & 0.263 \\
\hline TNF- $\alpha(\mathrm{pg} / \mathrm{mL})$ & 152.00 & $108.17-210.00$ & & 184.33 & $92.00-316.83$ & & 0.965 \\
\hline Cathepsin K & 235.71 & $154.96-354.76$ & & 132.94 & $94.84-292.66$ & & 0.056 \\
\hline
\end{tabular}

In contrast to our study, Xue et al. ${ }^{22}$ reported decreased levels of OPG in RA patients.

We evaluated TNF- $\alpha$ levels, a proinflammatory cytokine, and its correlation with other parameters, because TNF- $\alpha$ has an important role in RA. The authors ${ }^{23,24}$ reported that TNF- $\alpha$ aggravates the inflammation response, and leads to the acceleration of joint cartilage destruction. Moreover, particularly interleukin 17 and TNF- $\alpha$ together show a synergistic effect during the early phase of RA, and the levels of these two cytokines are closely associated with joint deterioration. ${ }^{23}$ In accordance with these findings, we observed higher levels of TNF- $\alpha$ in RA patients than the controls. Therefore, this cytokine is involved in bone damage in RA patients. Since TNF- $\alpha$ stimulates the expression of RANKL on the cell surface of mature osteoclasts, ${ }^{24}$ the increased serum level of this cytokine accompanying with RANKL is a significant finding of the present study.

Matrixmetalloproteinases contribute to joint damage and are considered the most important matrix-degrading enzymes in RA. ${ }^{25}$ MMP-3 (also known as human fibroblaststromelysin) is a secreted metalloprotease which plays role in the destruction of cartilage and bone in RA. ${ }^{26}$ MMP-3 activity, which originates directly from the inflamed joints, was significantly higher in RA patients in this study. This result was similar with the data reported on Nah et al.'s study. ${ }^{25}$ Since MMPs are produced by fibroblasts, macrophages, synovial cells and chondrocytes in response to proinflammatory cytokines such as TNF- $\alpha,{ }^{27,28}$ we thought that increased MMP-3 activity may be secondary to elevated TNF- $\alpha$ level in RA. In this study, MMP-3 activity was much higher in active group than inactive group. Consequently, we suggest that MMP-3 activity provides information about the activity of RA.

Circulating TRAP-5b activity is derived exclusively from osteoclasts and is a specific marker of bone resorption rate. ${ }^{29} \mathrm{We}$ observed no significant difference for TRAP-5b activities both between patient and control groups and between active and inactive patient groups. A possible mechanism is that, increased osteoprotegerin levels may downregulate the TRAP-5b activity. Also, the small size of patient group may be another cause of lower TRAP-5b activities in RA group.

Our results demonstrate that cathepsin $\mathrm{K}$ is elevated in the serum of patients with $\mathrm{RA}$ compared with that of a healthy control group. It is well accepted that cathepsin $\mathrm{K}$ is the major osteoclastic proteolytic enzyme responsible for bulk collagen degradation during bone remodeling. 
Wittrant et al. ${ }^{30}$ demonstrated OPG to be an inhibitor of cathepsin K. Human OPG inhibits cathepsin $\mathrm{K}$ and TRAP, both osteoclast markers. Whereas proinflammatory cytokines such as TNF- $\alpha$ induce the expression of cathepsin K. ${ }^{31}$ Consequently, increased cathepsin $\mathrm{K}$ activity in the sera of patients with RA may be related to increased TNF- $\alpha$ in this study. Our results were in accordance with the literature. ${ }^{32}$

Our study has some limitations. Firstly, the parameters analyzed were bone destruction markers, thus this study would be more useful and valuable if we had assessed patients radiologically. However, we were unable to evaluate association of these parameters with radiographic erosion due to the limited study time. Secondly, although RADAI, which was used for the assessment of disease activity, is an index correlating with Disease Activity Score in 28 joints, its association with bone destruction is controversial. ${ }^{33}$ For this reason, we did not evaluate the relationship of RADAI and bone destruction markers.

Based on the results of our study, increased levels of OPG, RANKL, TNF- $\alpha$, and MMP-3 and cathepsin $\mathrm{K}$ activities in RA patients suggest that these biomarkers play an important role in the disease process of RA. Therefore, we believe these parameters may be beneficial for clarification of the etiology, early diagnosis, and effective treatment of RA in the future. However, further studies are required to verify the presence of these parameters in patients with early RA, and their value as a prognostic factor for bone destruction in RA.

\section{Declaration of conflicting interests}

The authors declared no conflicts of interest with respect to the authorship and/or publication of this article.

\section{Funding}

The authors received no financial support for the research and/or authorship of this article.

\section{REFERENCES}

1. Walsh NC, Crotti TN, Goldring SR, Gravallese EM. Rheumatic diseases: the effects of inflammation on bone. Immunol Rev 2005 Dec;208:228-51.

2. Stewart A, Mackenzie LM, Black AJ, Reid DM. Predicting erosive disease in rheumatoid arthritis.
A longitudinal study of changes in bone density using digital X-ray radiogrammetry: a pilot study. Rheumatology (Oxford) 2004;43:1561-4.

3. Ritchlin CT, Schwarz EM, O'Keefe RJ, Looney RJ. RANK, RANKL and OPG in inflammatory arthritis and periprosthetic osteolysis. J Musculoskelet Neuronal Interact 2004;4:276-84.

4. Jones DH, Kong YY, Penninger JM. Role of RANKL and RANK in bone loss and arthritis. Ann Rheum Dis 2002;61 Suppl 2:ii32-9.

5. Pettit AR, Walsh NC, Manning C, Goldring SR, Gravallese EM. RANKL protein is expressed at the pannus-bone interface at sites of articular bone erosion in rheumatoid arthritis. Rheumatology (Oxford) 2006; 45:1068-76.

6. Wright HL, McCarthy HS, Middleton J, Marshall MJ. RANK, RANKL and osteoprotegerin in bone biology and disease. Curr Rev Musculoskelet Med 2009;2:56-64.

7. Lacey DL, Timms E, Tan HL, Kelley MJ, Dunstan CR, Burgess $\mathrm{T}$, et al. Osteoprotegerin ligand is a cytokine that regulates osteoclast differentiation and activation. Cell 1998;93:165-76.

8. Hofbauer LC, Heufelder AE. Role of receptor activator of nuclear factor-kappaB ligand and osteoprotegerin in bone cell biology. $\mathrm{J}$ Mol Med (Berl) 2001;79:243-53.

9. Hou WS, Li Z, Gordon RE, Chan K, Klein MJ, Levy $\mathrm{R}$, et al. Cathepsin $\mathrm{k}$ is a critical protease in synovial fibroblast-mediated collagen degradation. Am J Pathol 2001;159:2167-77.

10. Goto T, Yamaza T, Tanaka T. Cathepsins in the osteoclast. J Electron Microsc (Tokyo) 2003;52:551-8.

11. Chen $\mathrm{CH}$, Lin KC, Yu DT, Yang C, Huang F, Chen $\mathrm{HA}$, et al. Serum matrix metalloproteinases and tissue inhibitors of metalloproteinases in ankylosing spondylitis: MMP-3 is a reproducibly sensitive and specific biomarker of disease activity. Rheumatology (Oxford) 2006;45:414-20.

12. Zhu J, Yu DT. Matrix metalloproteinase expression in the spondyloarthropathies. Curr Opin Rheumatol 2006;18:364-8.

13. Halleen JM, Alatalo SL, Janckila AJ, Woitge HW, Seibel MJ, Väänänen HK. Serum tartrate-resistant acid phosphatase $5 \mathrm{~b}$ is a specific and sensitive marker of bone resorption. Clin Chem 2001;47:597-600.

14. Halleen JM, Tiitinen SL, Ylipahkala H, Fagerlund KM, Väänänen HK. Tartrate-resistant acid phosphatase 5b (TRACP $5 b$ ) as a marker of bone resorption. Clin Lab 2006;52:499-509.

15. Schett G, Stolina M, Dwyer D, Zack D, Uderhardt $S$, Krönke G, et al. Tumor necrosis factor alpha and RANKL blockade cannot halt bony spur formation in experimental inflammatory arthritis. Arthritis Rheum 2009;60:2644-54.

16. Keller C, Webb A, Davis J. Cytokines in the seronegative spondyloarthropathies and their modification by TNF blockade: a brief report and literature review. Ann Rheum Dis 2003;62:1128-32. 
17. Arnett FC, Edworthy SM, Bloch DA, McShane DJ, Fries JF, Cooper NS, et al. The American Rheumatism Association 1987 revised criteria for the classification of rheumatoid arthritis. Arthritis Rheum 1988;31:315-24.

18. Stucki G, Liang MH, Stucki S, Brühlmann P, Michel BA. A self-administered rheumatoid arthritis disease activity index (RADAI) for epidemiologic research. Psychometric properties and correlation with parameters of disease activity. Arthritis Rheum 1995;38:795-8.

19. Teitelbaum SL. Bone resorption by osteoclasts. Science 2000;289:1504-8.

20. Oelzner P, Franke S, Lehmann G, Eidner T, Müller A, Wolf $\mathrm{G}$, et al. Soluble receptor activator of NFkappa B-ligand and osteoprotegerin in rheumatoid arthritis relationship with bone mineral density, disease activity and bone turnover. Clin Rheumatol 2007;26:2127-35.

21. Ellabban AS, Kamel SR, Ahmed SS, Osman AM. Receptor activator of nuclear factor kappa B ligand serum and synovial fluid level. A comparative study between rheumatoid arthritis and osteoarthritis. Rheumatol Int 2012;32:1589-96.

22. Xue Y, Cai T, Shi S, Wang W, Zhang Y, Mao $\mathrm{T}$, et al. Clinical and animal research findings in pycnodysostosis and gene mutations of cathepsin $\mathrm{K}$ from 1996 to 2011. Orphanet J Rare Dis 2011;6:20.

23. Kirkham BW, Lassere MN, Edmonds JP, Juhasz KM, Bird PA, Lee CS, et al. Synovial membrane cytokine expression is predictive of joint damage progression in rheumatoid arthritis: a two-year prospective study (the DAMAGE study cohort). Arthritis Rheum 2006;54:1122-31.

24. Hashizume M, Hayakawa N, Mihara M. IL-6 transsignalling directly induces RANKL on fibroblast-like synovial cells and is involved in RANKL induction by TNF-alpha and IL-17. Rheumatology (Oxford) 2008;47:1635-40.

25. Nah SS, Ha E, Mun SH, Won HJ, Chung JH. Effects of melittin on the production of matrix metalloproteinase-1 and -3 in rheumatoid arthritic fibroblast-like synoviocytes. J Pharmacol Sci 2008;106:162-6.

26. Ribbens C, Martin y Porras M, Franchimont N, Kaiser MJ, Jaspar JM, et al. Increased matrix metalloproteinase-3 serum levels in rheumatic diseases: relationship with synovitis and steroid treatment. Ann Rheum Dis 2002;61:161-6.

27. Schett G, Stolina M, Dwyer D, Zack D, Uderhardt S, Krönke G, et al. Tumor necrosis factor alpha and RANKL blockade cannot halt bony spur formation in experimental inflammatory arthritis. Arthritis Rheum 2009;60:2644-54.

28. Keller C, Webb A, Davis J. Cytokines in the seronegative spondyloarthropathies and their modification by TNF blockade: a brief report and literature review. Ann Rheum Dis 2003;62:1128-32.

29. Qin YJ, Zhang ZL, Zhang H, Hu WW, Liu YJ, Hu YQ, et al. Age-related changes of serum tartrate-resistant acid phosphatase $5 \mathrm{~b}$ and the relationship with bone mineral density in Chinese women. Acta Pharmacol Sin 2008;29:1493-8.

30. Wittrant Y, Couillaud S, Theoleyre S, Dunstan C, Heymann D, Rédini F. Osteoprotegerin differentially regulates protease expression in osteoclast cultures. Biochem Biophys Res Commun 2002;293:38-44.

31. Hou WS, Li W, Keyszer G, Weber E, Levy R, Klein MJ, et al. Comparison of cathepsins $\mathrm{K}$ and $\mathrm{S}$ expression within the rheumatoid and osteoarthritic synovium. Arthritis Rheum 2002;46:663-74.

32. Skoumal M, Haberhauer G, Kolarz G, Hawa G, Woloszczuk W, Klingler A. Serum cathepsin K levels of patients with longstanding rheumatoid arthritis: correlation with radiological destruction. Arthritis Res Ther 2005;7:R65-70.

33. Suppiah R, Doyle A, Rai R, Dalbeth N, Lobo M, Braun J, et al. Quantifying bone marrow edema in the rheumatoid cervical spine using magnetic resonance imaging. J Rheumatol 2010;37:1626-32. 